\title{
DIAGNÓSTICO AMBIENTAL E PROPOSTA DE PLANO DE RECUPERAÇÃO DA APP DO CÓRREGO SUSSUAPARA, PALMAS - TO
}

\author{
LIMA, Arlete Leite ${ }^{1}$ \\ SOUZA, Patrícia Aparecida de ${ }^{2}$ \\ OLIVEIRA, Adriana Gonçalves ${ }^{1}$ \\ CARVALHO, Marla Guedes Cordeiro ${ }^{1}$ \\ SILVA, Rubens Ribeiro $\mathrm{da}^{3}$
}

ISSUE DOI: $10.3738 / 1982.2278 .2149$

\begin{abstract}
RESUMO: A mata ciliar constitui faixa de vegetação ao longo de um corpo hídrico. Confere ao recurso hídrico proteção contra o processo erosivo, melhora a condição microclimática e é abrigo e fonte de alimento à fauna terrestre e aquática. Os corpos hídricos de maneira geral, e em especial os rios e córregos, são um dos ecossistemas que mais vem sendo alterados pelas atividades antrópicas, principalmente quando inseridos no meio urbano. Dessa forma, este trabalho objetivou realizar um diagnóstico ambiental na área de preservação permanente do Córrego Sussuapara, em Palmas - TO e sugerir um plano de recuperação de áreas degradadas. Foi realizada uma visita a campo na área de estudo, coletando informações sobre a área de interesse por meio de apontamento e registro fotográfico, por meio de aplicação de Check-list, rede de interação e matriz de interação. Por meio do diagnóstico ambiental avaliou-se que o Córrego Sussuapara apresenta áreas onde houve a supressão da mata de galeria, que teve como efeito o encadeamento de diversos impactos ambientais. $\mathrm{O}$ aspecto mais atingido foi o meio biótico, fauna e flora, e físico, fator água. As medidas mitigadoras propostas foram isolar a área dos fatores de degradação, eliminar a emissão de efluentes e deposição de resíduos sólidos, retirar as espécies invasoras e conduzir a regeneração natural e/ou enriquecimento da área.
\end{abstract}

Palavras-Chave: Impacto ambiental. Rede de interação. Degradação ambiental. Medidas mitigadoras.

SUMMARY: The gallery forest vegetation strip is along a water body. Gives the water resource protection against erosion, improves the microclimate condition and is shelter and food source for terrestrial and aquatic fauna. The water bodies in general, and especially the rivers and streams, are one of the ecosystems that comes more being changed by human activities, especially when inserted in the urban environment. Thus, this study aimed to carry out an environmental assessment in the area of permanent preservation Stream Sussuapara in Palmas - TO and suggest a recovery plan for degraded areas. a visit to the field in the study area was carried out by collecting information on the area of interest by pointing and photographic record through application Checklist, network interaction and interaction matrix. Through the environmental assessment it was evaluated that the Stream Sussuapara shows areas where there was suppression of the gallery forest, which had the effect of chaining several environmental impacts. Hardest hit was the aspect biota, fauna and flora, and physical, factor water. The mitigation measures proposed was to isolate the area of degradation factors, eliminate the emission of effluents and solid waste disposal, remove invasive species and lead to natural regeneration and / or enrichment of the area.

Keywords: Environmental impact. Interaction Network. Ambiental degradation. Mitigatory measures.

\section{INTRODUÇÃO}

A mata ciliar constitui faixa de vegetação ao longo de um corpo hídrico. Confere ao recurso hídrico proteção contra o processo erosivo, melhora a condição microclimática e é abrigo e fonte de

\footnotetext{
${ }^{1}$ Engenheira Florestal, Mestranda do programa de pós-graduação em Ciências Florestais e Ambientais, UFT, Campus de Gurupi, Rua Badejós, Chácaras 69/72, Lote 7 - Zona Rural, Gurupi, Tocantins, CEP77402 - 970

${ }^{2}$ Professora Doutora do Curso de Engenharia Florestal da UFT, Campus de Gurupi, Rua Badejós, Chácaras 69/72,

Lote 7 - Zona Rural, Gurupi, Tocantins, CEP77402 - 970

${ }^{3}$ Prof. Dr. do Curso de Agronomia da Universidade Federal do Tocantins - UFT.
} 
alimento à fauna terrestre e aquática (LIMA;ZAKIA, 2004).

A conservação ou recuperação das matas ciliares constitui estratégia principal para preservação do corpo hídrico (MATIELLO et al., 2015). Os recursos hídricos de maneira geral, e em especial os rios e córregos, são um dos ecossistemas que mais vem sendo alterados pelas atividades antrópicas, principalmente quando inseridos no meio urbano. A intensa ocupação das margens fluviais tem sido responsável pela degradação desses hábitats aquáticos, tendo em vista que a qualidade desses ecossistemas é extremamente associada às condições do meio físico onde estão inseridos (SOUZA; BULHÕES, 2015).

A transformação das matas de ciliares degradadas, como resultado da recuperação do solo, pode oferecer condições de interdisciplinaridade como alternativas socioeconômicas e lúdicas para conter o processo de degradação de áreas verdes urbanas (CARNEIRO et al., 2016). Para tanto, é necessário a preparação de planos de recuperação de áreas degradadas, buscando à contensão da erosão e o conhecimento do nível dos impactos gerados por tais medidas sobre a qualidade do solo representa o fundamento básico para a busca de tal transformação (FOLEY et al., 2005).

$\mathrm{Na}$ preparação de um plano de recuperação de áreas degradadas, é aconselhado a execução incialmente um diagnóstico ambiental na área que se deseja estudar (GONÇALVES, et al., 2016). Sendo o "Check-list", ainda, um método de baixo custo para o diagnóstico do ambiente a ser estudado, podendo ser aplicado por pessoas sem conhecimento técnico especializado, proporcionando a conscientização da sociedade para preservação de seus recursos hídricos (BIZZO et al., 2014).

Existem diversas metodologias para realização do diagnóstico ambiental, tais metodologias devem seguir um procedimento que consista em um pacote de normas que variem de forma a adequar-se com o fator ambiental considerado, além de serem métodos flexíveis, aplicáveis em qualquer fase do processo e revisados constantemente (CREMONEZ et al., 2014).

A região onde está inserida a microbacia do Córrego Sussuapara por constituir um ambiente com ocupação humana, torna-se um local sensível às gradativas transformações antrópicas, à medida que se intensificam em frequência e intensidade, o desmatamento, a ocupação irregular, a erosão e o assoreamento (BARBOSA et al., 2005).

Nesse contexto, e reconhecendo que esse tipo de área apresenta grande valor para a população de Palmas, faz-se necessário direcionar esforços no sentido de compreender, em base científica, os reais impactos (positivos e negativos) causados pela ocupação antrópica nas áreas de preservação permanente do Córrego Sussuapara.

Portanto, o objetivo deste trabalho foi realizar um diagnóstico ambiental na área de preservação permanente do Córrego Sussuapara, no plano diretor norte do município de Palmas - TO e sugerir um plano de recuperação de áreas degradadas.

\section{MATERIAL E MÉTODO}

O estudo foi realizado em julho de 2016, a área está localizada na Região Norte do município de Palmas - TO, com coordenadas UTM 794007 e 8874083 (nascente) e 789933 e 8874682 (foz). A classificação climática de Palmas, de acordo com Köppen-Geiger, é do tipo clima úmido com moderada deficiência hídrica no inverno C2WA'a', sendo caracterizada por duas estações bem definidas, uma seca e a outra chuvosa (SILVA JUNIOR, 2016) (Figura 1). 
Figura 1. Localização geográfica do município de Palmas - TO.

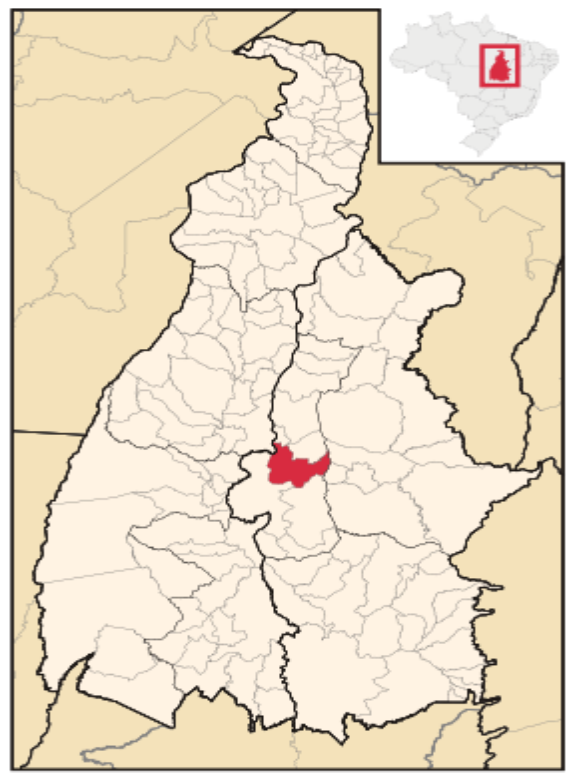

Fonte:Wikipedia (2016)

O estudo foi executado ao longo da calha do Córrego Sussuapara, que está inserido dentro do bioma cerrado e se localiza inteiramente dentro do perímetro urbano na região norte da cidade e desagua na Usina Hidrelétrica Lajeado, com uma área de aproximadamente $12,8 \mathrm{~km}^{2}$ e extensão de 4,40 km (Figura 02), (PREFEITURA MUNICIPAL DE PALMAS, 2014).

Figura 02: Localização do Córrego Sussuapara, com destaque para os trechos onde foi efetivado o estudo.

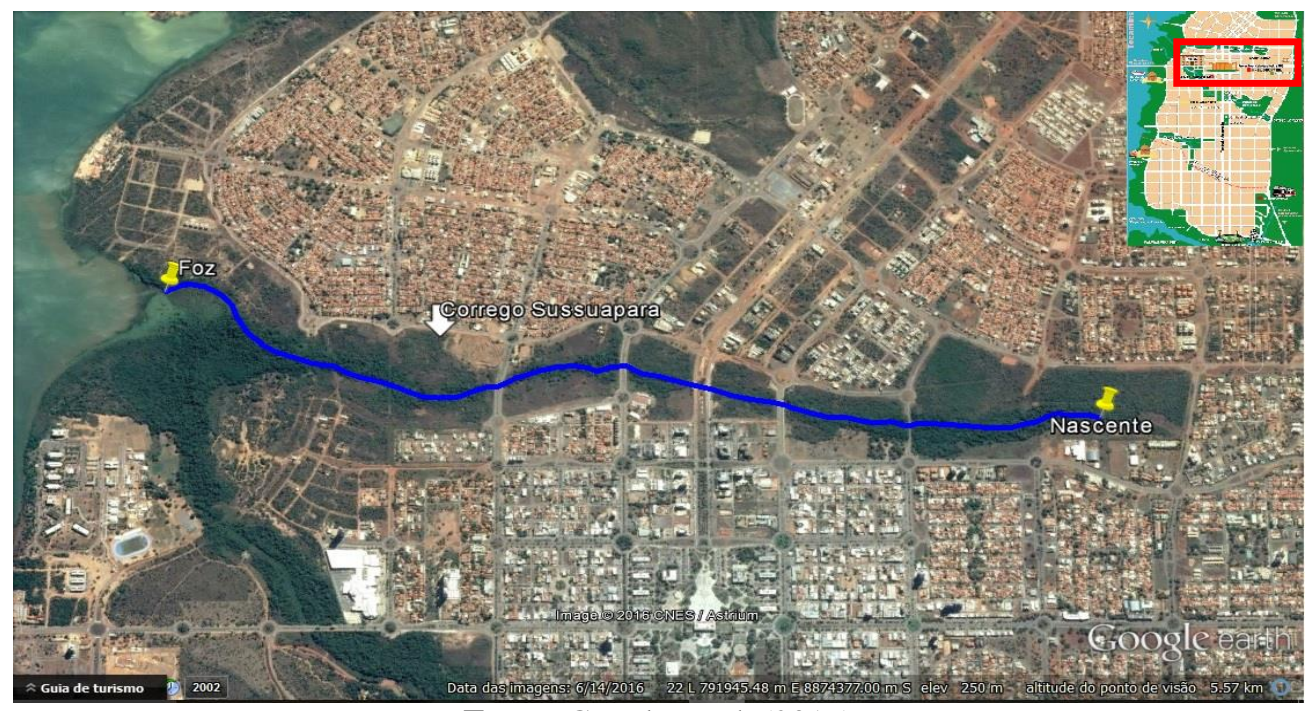

Fonte: Google Earth (2016)

Para o levantamento de dados primários realizou-se uma visita a campo na área de estudo, coletando informações sobre a área de interesse por meio de apontamento e registro fotográfico. Esse levantamento ocorreu por meio de aplicação de Check-list descritivo. A descrição e análise da condição atual da área feita pelas principais ações impactantes observados no local e utilizando-se de uma listagem simples das atividades impactantes ocorridos. E posteriormente, com a montagem da rede de interação de impactos e a combinação e ponderação de atributos (critérios qualitativos), fundamentando-se pela literatura de Sánchez (2006). 
A avaliação qualitativa dos impactos foi feita segundo os seguintes parâmetros estabelecidos pela Resolução nº 001/86 (BRASIL,1986), adaptado por Oliveira et al., (2015a), apresentado no Quadro 01:

Quadro 01: Parâmetros de análise qualitativa dos impactos.

\begin{tabular}{|c|c|c|}
\hline \multirow[b]{2}{*}{ Critério de ordem } & Direto (D) & Resulta em uma simples relação de causa e efeito. \\
\hline & Indireto (I) & $\begin{array}{l}\text { Resulta de uma ação secundária ou quando é parte } \\
\text { de uma cadeia de reações, também denominada de } \\
\text { Impacto Secundário. }\end{array}$ \\
\hline \multirow{2}{*}{ Critério de valor } & Positivo (P) & $\begin{array}{l}\text { Resulta em um dano à qualidade de um fator ou } \\
\text { parâmetro ambiental. }\end{array}$ \\
\hline & Negativo (N) & $\begin{array}{l}\text { Resulta na melhoria de um fator ou parâmetro } \\
\text { ambiental. }\end{array}$ \\
\hline \multirow{3}{*}{ Critério de dinâmica } & Temporário (T) & Possui duração limitada. \\
\hline & Permanente (PE) & $\begin{array}{l}\text { Não cessa num período conhecido, permanecendo } \\
\text { mesmo após cessar a ação. }\end{array}$ \\
\hline & Cíclico (C) & $\begin{array}{l}\text { Quando o efeito se manifesta em intervalos de } \\
\text { tempo determinados. }\end{array}$ \\
\hline \multirow{3}{*}{ Critério de tempo } & Curto Prazo (CP) & A ação permanece num curto espaço de tempo. \\
\hline & Médio Prazo (MP) & A ação pode ser cessada após um tempo. \\
\hline & Longo Prazo (LP) & O impacto pode ser considerado irreversível. \\
\hline \multirow[b]{2}{*}{ Critério de plástica } & Reversível (R) & O local pode voltar a ter a paisagem original. \\
\hline & Irreversível (IR) & $\begin{array}{l}\text { Após a ação impactante, mesmo com medidas } \\
\text { mitigadoras, o local não volta a ter a paisagem } \\
\text { original. }\end{array}$ \\
\hline \multirow{3}{*}{ Critério de espaço } & Local (LC) & $\begin{array}{l}\text { Quando afeta apenas a área local do } \\
\text { empreendimento. }\end{array}$ \\
\hline & Regional (RG) & $\begin{array}{l}\text { Quando o efeito extrapola a área de implantação do } \\
\text { empreendimento. }\end{array}$ \\
\hline & Estratégico (E) & $\begin{array}{l}\text { Quando o efeito assume reflexo estadual ou } \\
\text { nacional. }\end{array}$ \\
\hline
\end{tabular}

Fonte: Oliveira et al., 2015a.

Para a análise quantitativa adotou-se a rede de interações com os valores de magnitude e importância, com os valores entre 1 e 10, como técnica para mensuração dos impactos ambientais existentes. A matriz empregada foi derivada de Leopold et al., (1971) e adaptada por Silva (1994), tornase assim possível analisar todos os impactos ambientais que ocorrerão na área, além de possibilitar a identificação dos impactos mais importantes para os meios biótico, físico e antrópico analisados.

Após a concretização e conclusão dessas metodologias, foi organizada uma proposta de recuperação da área degradada, sugerindo-se o modelo de mais adequado para o local.

\section{RESULTADO E DISCUSSÃO}

Por meio do diagnóstico ambiental realizado na Área de Preservação Permanente (APP) do Córrego Sussuapara, os impactos ambientais mais importantes observados foram classificados e caracterizados no Check-list, foram (Tabela 1): 
Tabela 1. Classificação das ações impactantes e dos impactos encontrados ao longo do Córrego Sussuapara - Palmas/TO.

\begin{tabular}{|l|l|l|l|l|l|l|}
\hline $\begin{array}{c}\text { Impactantes/ } \\
\text { Impactos }\end{array}$ & $\begin{array}{c}\text { Retirada de } \\
\text { vegetação } \\
\text { ripária }\end{array}$ & $\begin{array}{c}\text { Exposição } \\
\text { do solo }\end{array}$ & $\begin{array}{c}\text { Compactaçã } \\
\text { o do solo }\end{array}$ & $\begin{array}{c}\text { Assoreament } \\
\text { o }\end{array}$ & $\begin{array}{c}\text { Presença de } \\
\text { vegetação } \\
\text { exótica }\end{array}$ & $\begin{array}{c}\text { Poluição } \\
\text { por } \\
\text { resíduos } \\
\text { sólidos }\end{array}$ \\
\hline Ordem & $\mathrm{D}$ & $\mathrm{IN}$ & $\mathrm{IN}$ & $\mathrm{IN}$ & $\mathrm{IN}$ & $\mathrm{D}$ \\
\hline Valor & $\mathrm{N}$ & $\mathrm{N}$ & $\mathrm{N}$ & $\mathrm{N}$ & $\mathrm{N}$ & $\mathrm{N}$ \\
\hline Dinâmica & $\mathrm{PE}$ & $\mathrm{PE}$ & $\mathrm{PE}$ & $\mathrm{PE}$ & $\mathrm{PE}$ & $\mathrm{PE}$ \\
\hline Tempo & $\mathrm{MP}$ & $\mathrm{CP}$ & $\mathrm{LP}$ & $\mathrm{LP}$ & $\mathrm{MP}$ & $\mathrm{CP}$ \\
\hline $\begin{array}{l}\text { Plástica } \\
\text { Espaço }\end{array}$ & $\mathrm{R}$ & $\mathrm{R}$ & $\mathrm{R}$ & $\mathrm{R}$ & $\mathrm{R}$ & $\mathrm{R}$ \\
\hline
\end{tabular}

Legenda - Positivo (P), Negativo (N), Direto (D), Indireto (IN), Local (LC), Regional (RG), Estratégico (E), Curto prazo (CP), Médio prazo (MP), Longo prazo (LP), Temporário (T), Cíclico (C), Permanente (PE), Reversível (R), Irreversível (IR).

A remoção da vegetação ciliar, seja por desmatamento ou queimadas, é considerada de valor negativo e ordem direta que, por conseguinte, gera outros impactos ao ambiente (Tabela 1). E poderão provocar efeitos adversos no ambiente com diferentes espaços, como a exposição do solo e afugentamento da fauna, podendo deixar de ser local para regional, pois o efeito se propaga para além das intermediações da área em estudo, num médio prazo de tempo, de dinâmica permanente e plástica reversível, (Tabela 1) (Figura 3).

Figura 3. Córrego Sussuapara, próximo à nascente, supressão de vegetação da Área de Presevação Permanente (APP) - Palmas - TO.

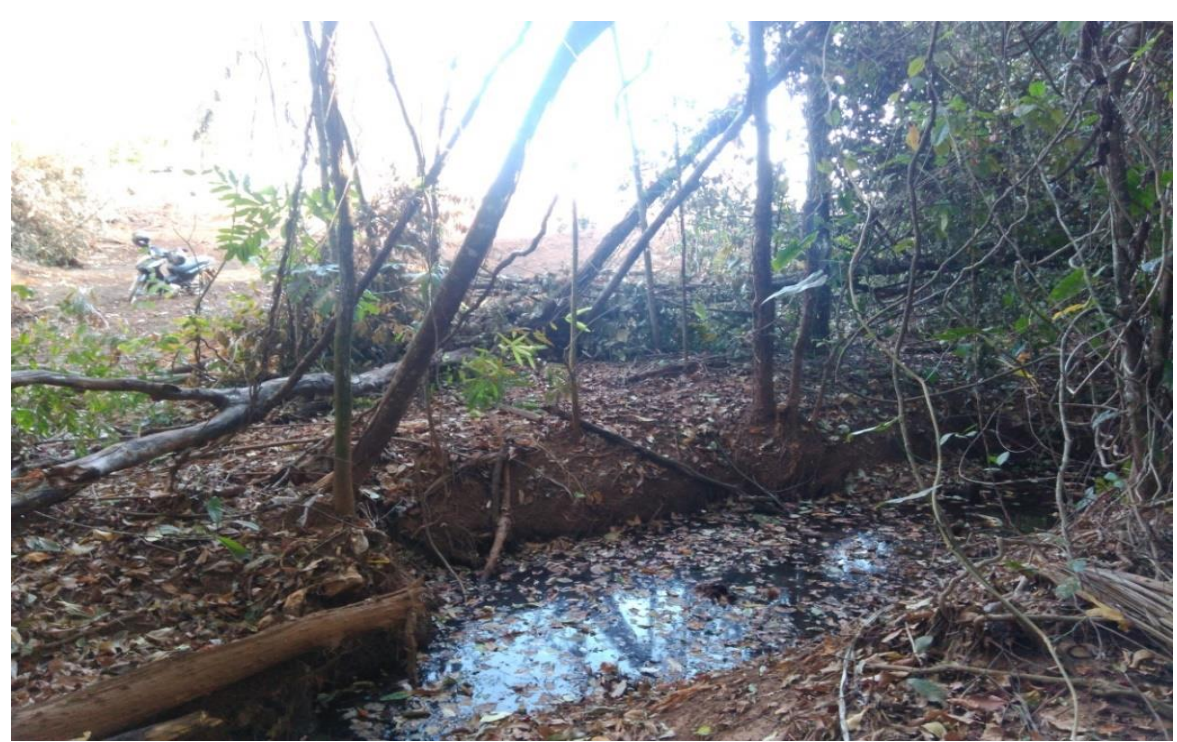

Fonte: Arquivo dos Autores (2016)

Para Mesquita Monteiro e Ramos Oliveira (2014), a mata riparia se constitui num importante elemento de manutenção do equilíbrio ambiental das áreas em que se localizam, pois conferem proteção ao solo, à fauna, a flora e aos ambientes aquáticos.

Barbosa et al., (2005), estudando a unidade de conservação do Córrego Sussuapara, também, encontram diversos impactos como a remoção da cobertura vegetal, recepção de galerias pluviais e práticas indiscriminada de queimadas, além do uso do manancial para fins recreativos, (Figura 4). 
Figura 4. Vegetação ripária danificada pelo fogo em APP, Córrego Sussuapara - Palmas - TO.

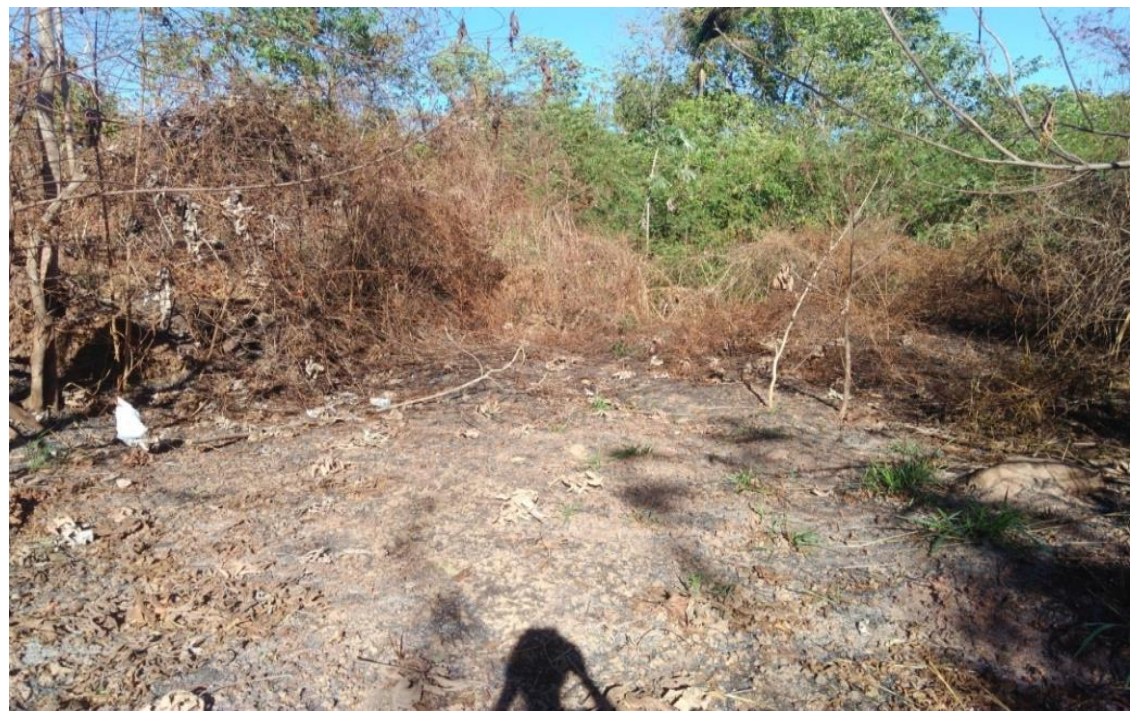

Fonte: Arquivo dos Autores (2016)

A supressão da mata ciliar é uma das razões mais comuns para o início dos processos erosivos com a exposição dos solos favorecendo a ação do assoreamento do curso d'água (LUANE SILVA et al., 2016). Na área de estudo o assoreamento é decorrente do carreamento de partículas sólidas de áreas próximas com o solo descoberto (Figura 5). Gonçalves et al., (2016) relatam que o solo exposto faz com que torne mais rápido o carregamento de materiais orgânicos, inorgânicos e fragmentos desagregadas do solo para água.

Este problema é causado pela atuação antrópica, visto que o tipo de uso e ocupação das margens do referido córrego, ante a supressão da mata ripária que evitaria, em parte, o assoreamento do rio.

Figura 5. Solo exposto e compactado área próxima à APP do Córrego Sussuapara, pista de motocross Palmas - TO.

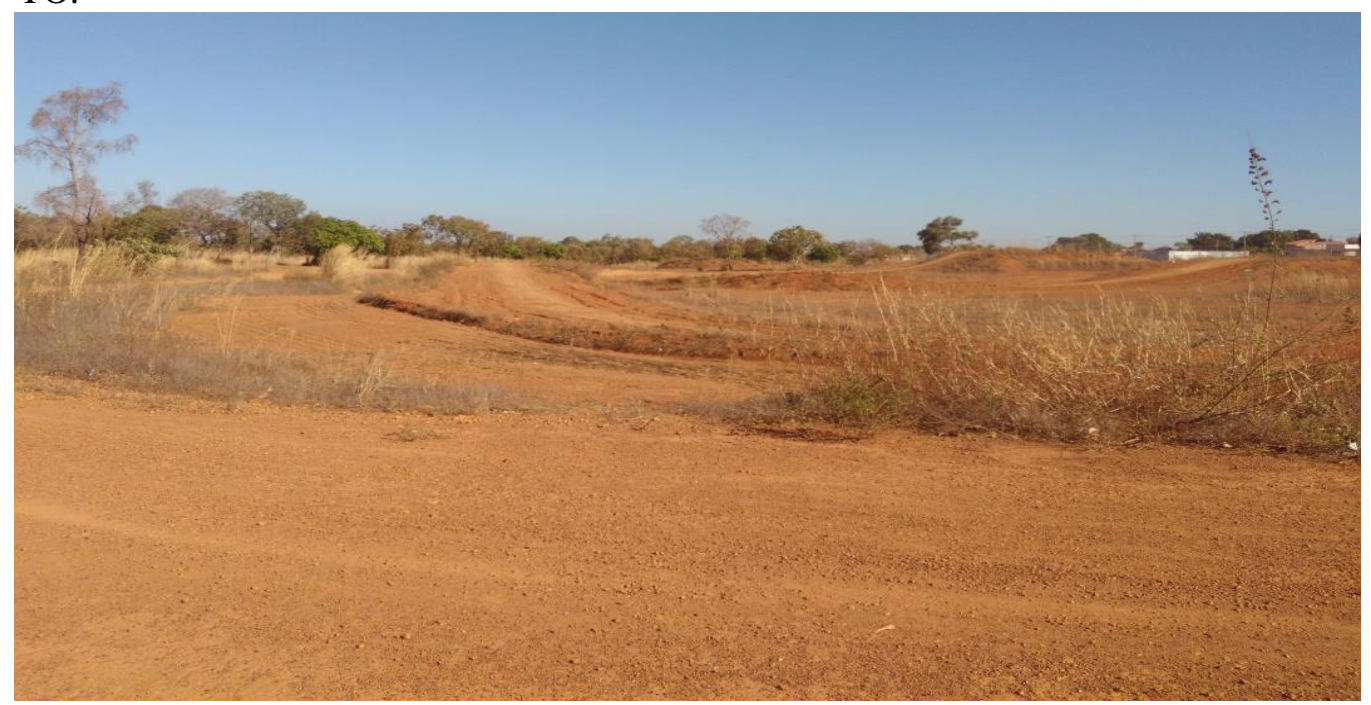

Fonte: Arquivo dos Autores (2016)

No Córrego Sussuapara os impactos causados pelo assoreamento foram considerado de valor negativo e de ordem indireto, (Tabela 1). Exibindo um espaço regional, dinâmica de caráter permanente, longo prazo e plástica reversível, a partir de ações de recuperação e minimização do impacto, como a dragagem da areia da calha do rio e a revegetação das áreas desmatadas, (Figura 6). 
Figura 6. Assoreamento, área próximo à nascente, do Córrego Sussuapara, Palmas - TO.

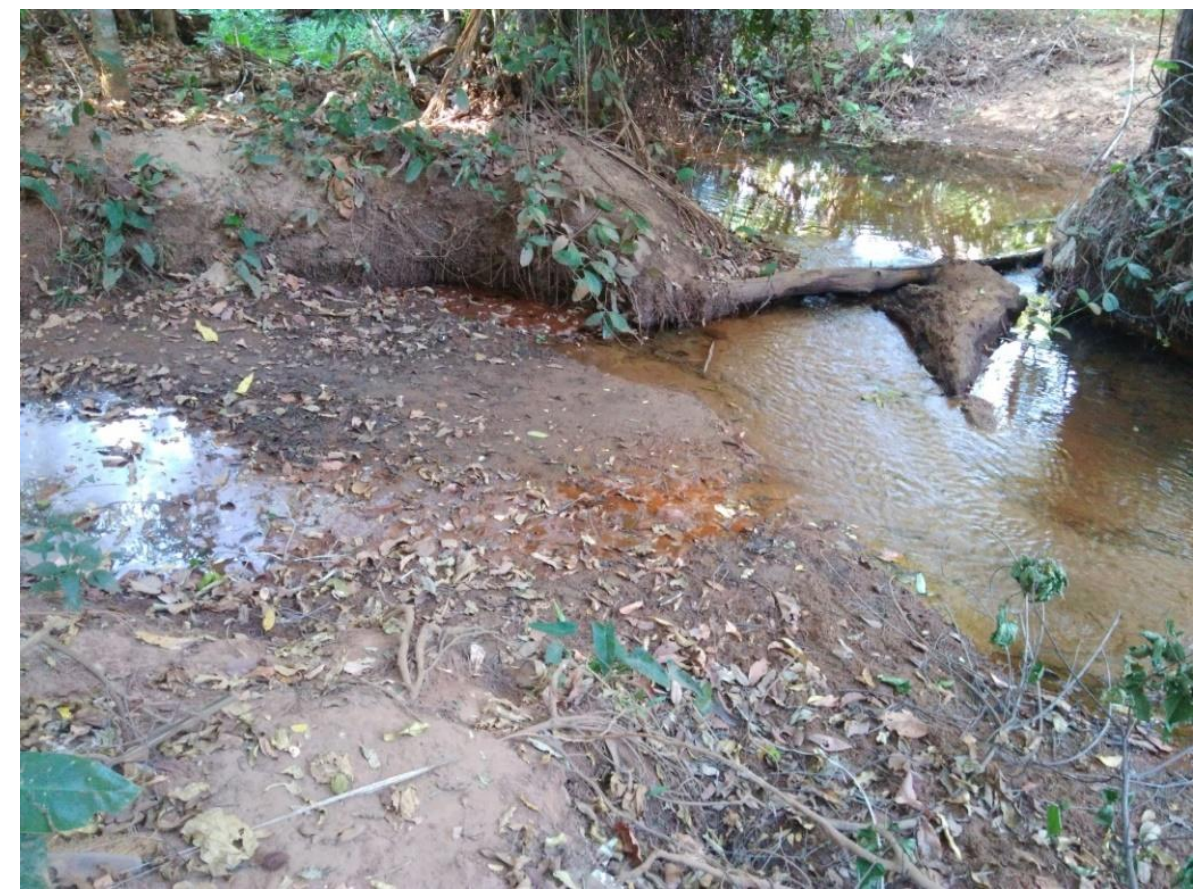

Fonte: Arquivo dos Autores (2016)

O assoreamento dos cursos d'águas é um grande problema para a conservação das condições normais dos corpos hídricos, causam desequilíbrios e alterações nos seus aspectos hidrodinâmicos, que com o passar do tempo facilitam o surgimento de bancos de areias no seu leito (NUNES; GOMES; PAULA, 2014).

A compactação do solo na área em estudo mostrou-se com dinâmica permanente, plástica reversível e de longo prazo. Além de apresentar valor negativo e ordem indireta num espaço local, (Tabela 1). Esse fato é responsável por colaborar com o aumento da ação da erosão na área e consequente assoreamento da calha do recurso hídrico, alterando assim a qualidade da água e do solo.

A poluição por resíduos sólidos é um impacto de valor negativo e ordem direta. Além de ter um caráter local, curto prazo, de dinâmica permanente e plástica reversível, (Tabela 1). A poluição representa um dos principais problemas para a maior parte dos recursos hídricos em todo o mundo, podendo trazer graves consequências ambientais e econômicas (SOUZA;SILVA, 2015).

A inserção do Córrego Sussuapara dentro do espaço urbano propicia também uma descarga urbana composta por materiais diversos, dentre as quais muitas são compostas de efluentes domésticos, metais pesados, resíduos sólidos, etc. A região onde está inserida a microbacia do Córrego Sussuapara por constituir um ambiente com ocupação humana, torna-se um local sensível às gradativas transformações antrópicas (BARBOSA et al., 2005).

Pimenta et al., (2016) relatam que resíduos sólidos dispostos inadequadamente no meio urbano são fontes de contaminação dos recursos hídricos, de contribuição para o assoreamento, de enchentes, de proliferação de vetores transmissores de doenças, de poluição visual, de contaminação do ambiente, entre outros, (Figura 7). 
Figura 7. Presença de resíduo sólido em APP, Córrego Sussuapara - Palmas - TO.

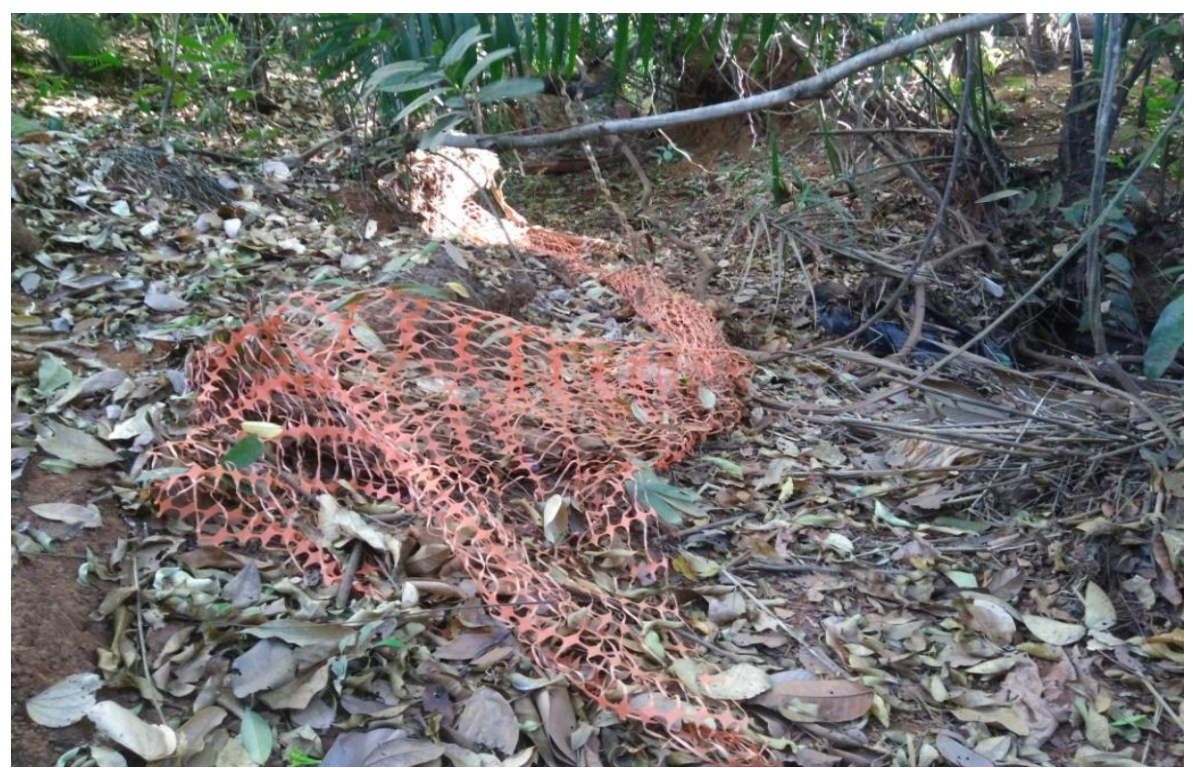

Fonte: Arquivo dos Autores (2016)

A Agência Nacional das Águas (ANA) destaca algumas atividades com grande potencial de degradação de matas ciliares, como a produção agrícola, indústrias e mineradoras, infraestrutura hídrica, e lançamentos de efluentes domésticos não ou parcialmente tratados no ambiente aquático (BRASIL, 2013).

A poluição hídrica é resultado de atividades antrópicas, podendo ser de origens doméstica, comercial ou industrial. Estas atividades são classificadas como fontes de poluição pontuais e difusas. As fontes de poluição pontuais são aquelas em que os poluentes atingem o curso d'água de maneira concentrada, sendo mais fácil a sua identificação. As indústrias e as estações de tratamento de esgoto são exemplos deste tipo de fonte. As fontes de poluição difusa são aquelas onde os poluentes atingem o curso d'água de uma forma aleatória, ao longo de sua extensão, dificultando a sua identificação e controle. Lançamento na drenagem pluvial é um dos principais exemplos deste tipo de fonte (Figura 8) (VON SPERLING, 2005).

Figura 8. Tubulação do sistema de drenagem de águas pluviais que deságua no Córrego Sussuapara Palmas - TO.

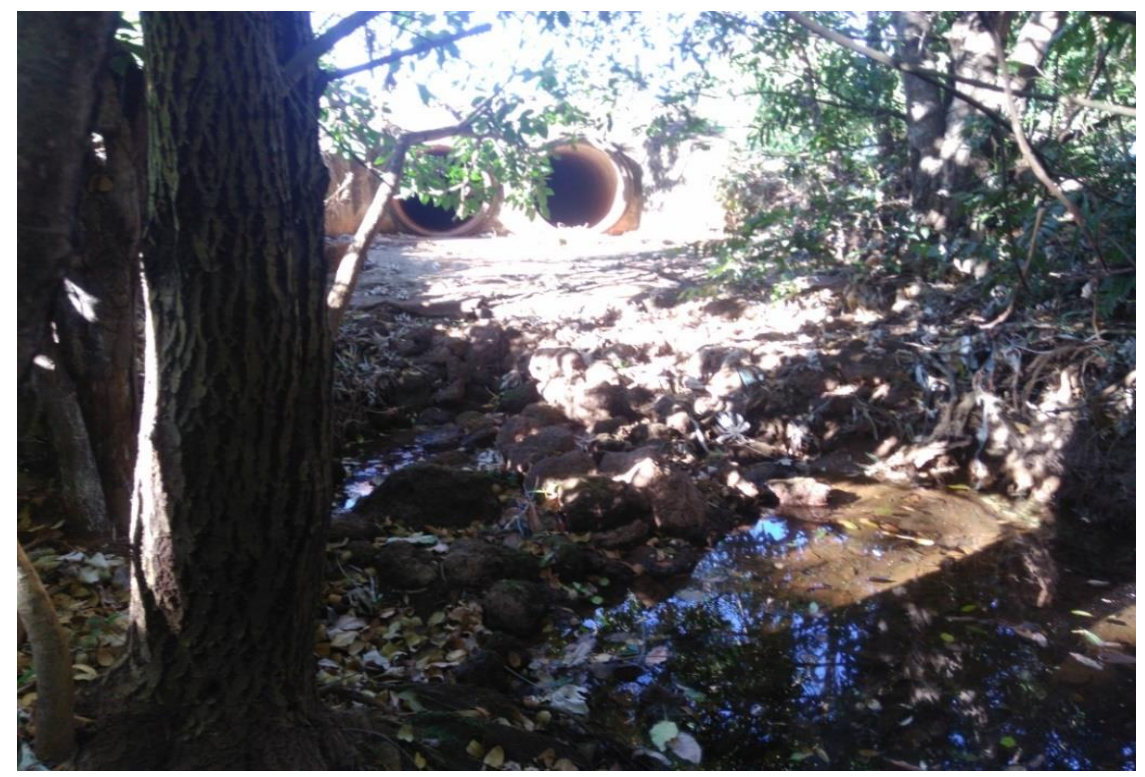

Fonte: Arquivo dos Autores (2016) 
A presença de vegetação exótica ao longo do Córrego Sussuapara é um impacto ambiental caracterizado como negativo e direto, de dimensões locais e curto prazo. Sendo um impacto permanente e reversível (Tabela 1). Essa vegetação encontra um local propício ao seu desenvolvimento (Figura 9).

Figura 9. Foz do Córrego Sussuapara no Lago da UHE Lajeado - Palmas - TO.

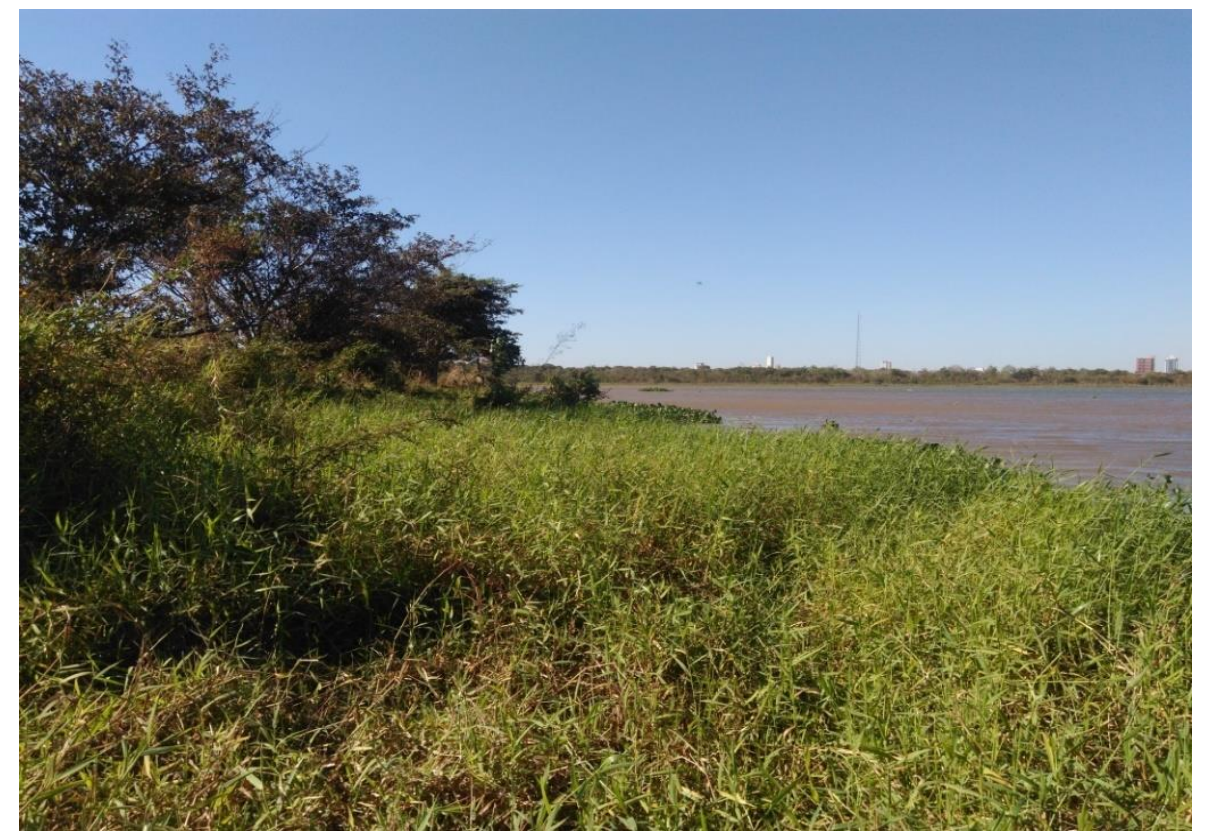

Fonte: Arquivo dos Autores (2016)

Na visita a campo verificou-se a presença de espécies exóticas tais como: gramíneas invasoras das variedades andropogom e brachiara, amêndoa; comigo-ninguém-pode; goiabeiras e mangueiras. Provavelmente estas espécies chegaram à área, trazidas pelas águas de chuvas que carreiam matérias de outras áreas e desaguam na calha do Córrego Sussuapara.

Segundo Tommasi (1993), a matriz de interação identifica impactos, de segunda e terceira ordem sendo uma metodologia que admite estabelecer um encadeamento dos impactos ambientais causados por uma ação (atividade) impactante como a retirada da vegetação original.

Com a supressão da vegetação ciliar, observou-se que houve uma perda da biodiversidade, com isso há um afugentamento da fauna, invasão de espécies de vegetais exóticas, alteração da qualidade da água e do solo, diminuição da população de polinizadores e dispersores de sementes. Como consequência da exposição do solo está o escoamento superficial que causa erosão, que causa diminuição da porosidade e da compactação e dificultando a infiltração da água no solo causando assoreamento (figura 10). 
Figura 10. Rede de interação das ações impactantes e dos impactos ambientais da APP, Córrego Sussuapara - Palmas - TO.

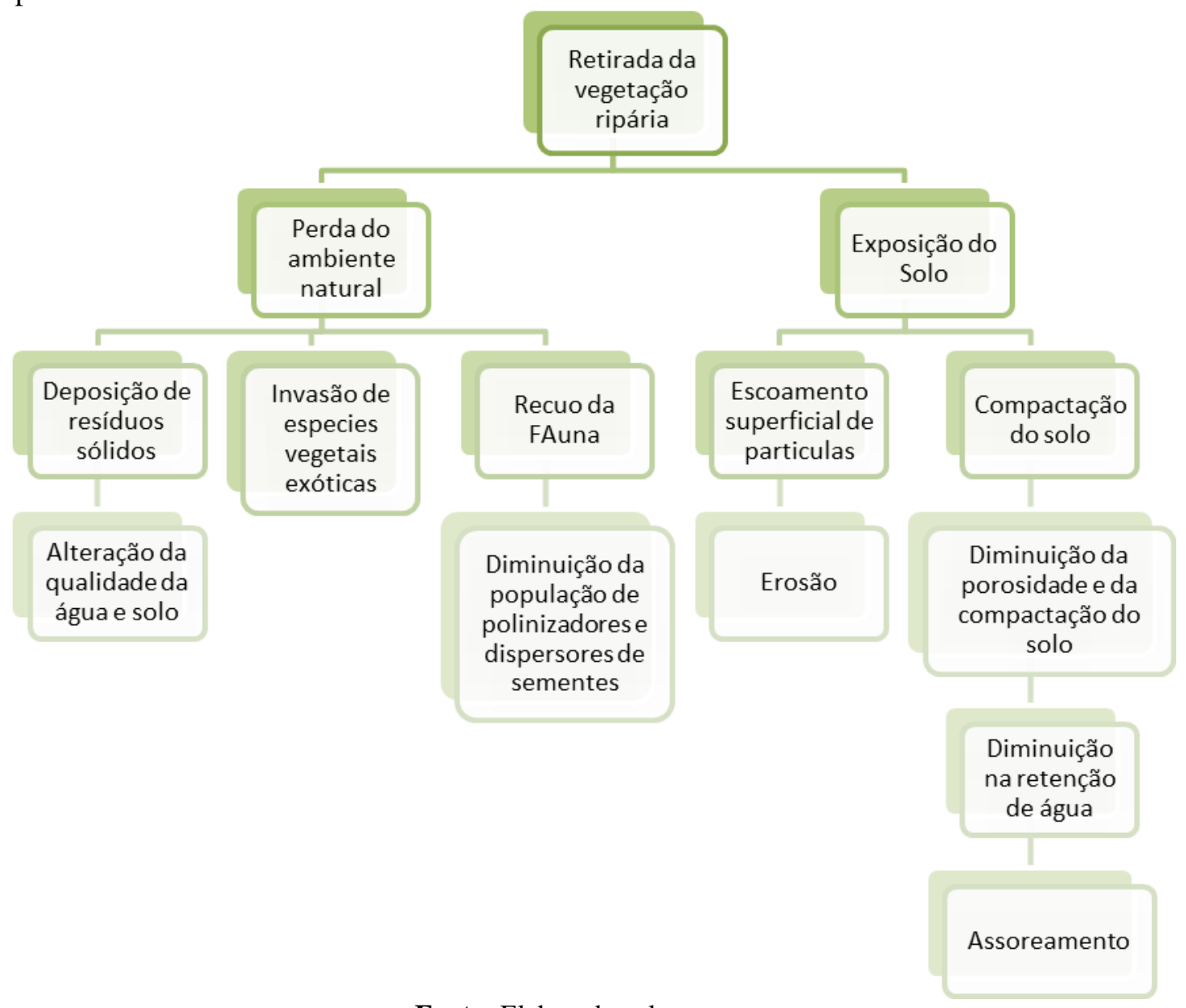

Fonte: Elaborada pelos autores

A matriz de interação é uma metodologia de apresentação dos impactos ambientais observados na área de estudo. Rizzeti et al., (2014) enfatizaram que os fluxogramas são uns dos artifícios mais utilizados para a representação desta matriz de interação. Dessa forma é organizando em uma sequência lógica de efeitos provocados por uma ação, iniciando-se pelo desmatamento, impacto de ordem direta, que estimula todos os outros impactos indiretos, como o recuo da fauna e assoreamento (RIZZETI et al., 2014).

Gonçalves et al., (2016) e Neres et al., (2015) também utilizaram a matriz de interações para realizar um diagnóstico ambiental e propor medidas mitigadoras para APP em municípios no sul do estado do Tocantins.

A matriz de interação de Leopold et al., (1971) é uma tabela de dupla entrada (Tabela 2), onde se apresenta com duas características principais: a magnitude e a importância, que constituem os pontos principais dos impactos ambientais, uma vez que informam sobre a significância dos mesmos. A magnitude é a grandeza de um impacto em termos absolutos, podendo ser definida como a medida de alteração de um atributo ambiental, em termos quantitativos ou qualitativos. A importância é a ponderação do grau de significância de um impacto em relação ao fator ambiental afetado e a outros impactos (SPADOTTO, 2002). 
Tabela 2. Matriz de Interação, baseada no modelo de Leopold et. al., (1971), adaptada por Silva (1994).

\begin{tabular}{|c|c|c|c|c|c|}
\hline \multicolumn{6}{|l|}{ MATRIZ DE INTERAÇÃO } \\
\hline \multirow{3}{*}{$\begin{array}{l}\text { Ações Impactantes/ Impactos } \\
\text { Encontrados }\end{array}$} & \multicolumn{5}{|c|}{ Fatores Ambientais Relevantes } \\
\hline & \multirow{2}{*}{$\begin{array}{l}\text { Meio Biótico } \\
\text { Flora e Fauna } \\
\end{array}$} & \multicolumn{3}{|c|}{ Meio Físico } & \multirow{2}{*}{$\begin{array}{l}\text { Meio } \\
\text { Antrópico }\end{array}$} \\
\hline & & Água & Solo & $\mathbf{A r}$ & \\
\hline \multirow{2}{*}{$\begin{array}{l}\text { Retirada da vegetação ripária } \\
\text { (Desmatamento e Queimadas) }\end{array}$} & $9 *$ & $8 *$ & $7 *$ & $8^{*}$ & $8^{*}$ \\
\hline & $9 * *$ & $6 * *$ & $6^{* *}$ & $5 * *$ & $7 * *$ \\
\hline \multirow{2}{*}{ Exposição do Solo } & 8* & $6 *$ & $9 *$ & $5^{*}$ & $6^{*}$ \\
\hline & $6 * *$ & $4 * *$ & $7 * *$ & $2 * *$ & $3 * *$ \\
\hline \multirow{2}{*}{ Compactação do solo } & $7 *$ & $8 *$ & $8^{*}$ & $4 *$ & $5^{*}$ \\
\hline & $4 * *$ & $5 * *$ & $6 * *$ & $3 * *$ & $4 * *$ \\
\hline \multirow{2}{*}{ Assoreamento } & $8^{*}$ & $9 *$ & $5^{*}$ & $3 *$ & $8^{*}$ \\
\hline & $6 * *$ & $7 * *$ & $3 * *$ & $1 * *$ & $6 * *$ \\
\hline \multirow{2}{*}{ Presença de vegetação exótica } & $6^{*}$ & 4* & $4 *$ & $4 *$ & $4 *$ \\
\hline & $4 * *$ & $2 * *$ & $2 * *$ & $3 * *$ & $2 * *$ \\
\hline \multirow{2}{*}{ Presença de Resíduos Sólidos } & $5^{*}$ & $8 *$ & $5^{*}$ & $7 *$ & $8^{*}$ \\
\hline & $3 * *$ & $6^{* *}$ & $2 * *$ & $4 * *$ & $7 * *$ \\
\hline MÉDIA & $\begin{array}{l}7,2^{*} \\
5,3^{* *}\end{array}$ & $\begin{array}{l}7,2^{*} \\
5,0^{* *}\end{array}$ & $\begin{array}{l}6,3^{*} \\
4,3^{* *}\end{array}$ & $\begin{array}{l}5,2 * \\
3,0 * *\end{array}$ & $\begin{array}{l}6,5^{*} \\
4,8^{* *}\end{array}$ \\
\hline
\end{tabular}

Legenda: *Valores de magnitude, ** Valores de importância.

Fonte: Elaborada pelos autores

As ponderações de maiores valores médios encontrados foram para o meio biótico, fauna e flora, e meio físico, especificamente a água, com 7,2 de magnitude cada, e 5,3 e 5,0 de importância, respectivamente, esse maior valor de magnitude, promulga a grandeza desse tipo de ato sobre o atributo ambiental. Seguida, por meio antrópico, com 6,5 de magnitude e 4,8 de importância, (Tabela 2).

Os fatores ambientais que apresentaram as menores médias foram o solo e o ar, com 6,3 e 5,2 de magnitude, respectivamente. E, 4,3 e 3,0 de importância, respectivamente, (Tabela 2). Esses valores refletem uma menor significância dos impactos ambientais nesses fatores.

Diversos autores utilizaram a rede de interação para mensurar os impactos ambientais nos mais diversos ambientes, principalmente, os impactos em APP e cursos hídricos. Gonçalves et al., (2016); Reis et. al., (2015) e Oliveira et al., (2015b) usaram matrizes de interação para mensurar os impactos ambientais de APP e sugerir a recuperação das áreas analisadas.

Com a aplicação do Check-list, rede e matriz de interação, verificou-se que a área estudada do Córrego Sussuapara, que sofreu degradação, causando impactos ambientais no meio biótico, físico e antrópico, por isso, faz-se necessário a adoção de medidas mitigadoras para reduzir o efeito desses.

Tendo a sua bacia totalmente inserida no limite urbano de Palmas, o Córrego Sussuapara está extremamente vulnerável aos efeitos da urbanização, como a ocupação das suas APPs e despejo de resíduos sólidos de forma clandestina.

As medidas mitigadoras propostas, que visam minimizar e/ou recuperar os impactos dos atos impactantes, foram elencadas após a concretização de toda a metodologia do diagnóstico ambiental, onde houve a avaliação, caracterização e classificação dos impactos observados na APP do Córrego Sussuapara.

Diversos autores descrevem a enorme importância da recuperação das áreas degradadas as margens dos recursos hídricos (GONÇALVES et al., 2016; VAZ;ORLANDO, 2012; CARMO et al., 2007). Com base no novo código florestal (Lei $\mathrm{n}^{\circ} 12.651 / 12$ ), as faixas de vegetação marginais de rios e 
córregos devem ser protegidas, cuja, faixa de proteção, que pode variar de 30 a $600 \mathrm{~m}$, é delimitada de acordo com a largura do curso d'água (BRASIL, 2013). A área em estudo não se encontra conforme a legislação pressupõe, com trechos ao longo de sua extensão com faixas de mata ciliares menores que 30 m, por isso propõe-se a adoção de um Projeto de Recuperação de Áreas Degradadas (PRAD).

Para dar início a ação de recuperação da APP do Córrego Sussuapara, deve-se isolar a área dos fatores que causam degradação, parar como a deposição de efluentes e resíduos sólidos de forma inadequada, a entrada de seres humanos, animais de grande porte, uso de fogo e retirada das espécies exóticas.

Vários trechos da APP do Córrego Sussuapara não sofreram com a supressão de vegetação ripária, mantendo grande acúmulo de espécies nativas da região, o que faz com que ocorra uma boa disponibilidade de sementes e propágulos para a recuperação das áreas onde houve a supressão da vegetação, e assim um enriquecimento do local, recuperando-o com um manejo apropriado do solo, através da regeneração natural.

Nos áreas onde isso não será possível, aconselha-se o plantio de mudas de espécies que promovam de forma mais rápida a recuperação da área. Gonçalves et al., (2016), igualmente, cita este de método de recuperação na sua proposta para recuperação de APP às margens da represa da Fazenda Santa Juliana em Cariri do Tocantins - TO.

Para o enriquecimento das faixas de mata ciliar do Córrego Sussuapara, dever-se-á plantar espécies que ocorram de forma natural na região. Na Tabela 3, tem-se listado as diversas espécies vegetais da bacia do Sussuapara, trabalho executado por Carmo et al., (2007).

Tabela 3. Espécies encontradas e identificadas na microbacia do Córrego Sussuapara, Palmas - TO.

(Continua)

\begin{tabular}{ll|ll}
\hline NOME VULGAR & NOME CIENTÍFICO & $\begin{array}{l}\text { NOME } \\
\text { VULGAR }\end{array}$ & NOME CIENTÍFICO \\
\hline Açoita cavalo & Luhea divaricata & Gonçalo Alves & Astronium flaxinifolium \\
Amargoso & Tupuana fusca & Imbaúba & Cecropia adenopus \\
Angelim & Andira humilis & Inharé & Brosimum sp \\
Angico branco & Piptadenia columbria & Hymenaea sp \\
vaqueiro & Macaúba & Acronomia sp \\
Araçá & Eugenia florida & Mamonianha & Esenbeckia febrifuga \\
Axixá & Astronium urundeuva & Manacá & Brunfelsia sp \\
Babaçu & Steculia sp & Mangaba & Hancomia speciosa \\
Bacaba & Orblgnya martiniana & Mata menino & Magonia pubescens \\
Bacupari & Reedia sp & Terminalia sp \\
Bananeira do & Salvertia convallariodora & Merindiba & Bauhinia forticata \\
campo & Suyphnodendron / & Murici & Byrsonima cressifolia \\
Barbatimão & babardetimam & Mutamba & Guazuma ulmifolia \\
Baru & Dipterys pterata & Licania rlgida \\
Bruto & Annona coriacea & Tapebuia caraíba \\
Buriti & Mauritia sp & Terminalia sp & Syagrus picrophyla \\
Cachamorra & Eugenia dysenterica & Euphorbia sp \\
Cagaita & Aracadium pumillum & Pati & Pau de leite \\
Caju do campo & Pau terra & Quales sp
\end{tabular}


Tabela 3. Espécies encontradas e identificadas na microbacia do Córrego Sussuapara, Palmas - TO.

\begin{tabular}{|c|c|c|c|}
\hline NOME VULGAR & NOME CIENTÍFICO & \begin{tabular}{|l|} 
NOME \\
VULGAR \\
\end{tabular} & NOME CIENTÍFICO \\
\hline Canela de ema & Vellozia laneta & Pequi & Caryocar brasilliensis \\
\hline Canjerana & Cabralea sp & Piaçaba & Orbygria eichieri \\
\hline Capim agreste & Panicum sp & Pindaíba & Xilopia $s p$ \\
\hline Capitão do campo & Terminalia argêntea & $\begin{array}{l}\text { Pitomba do } \\
\text { cerrado }\end{array}$ & Serjania sp \\
\hline Caraíba & Tabebuia caraíba & Puçá & Rauwolfa bahierisis \\
\hline Emburuçu & Bombax caithophorum & Sambaíba & Curatela sp \\
\hline Fava de bolota & Parkia sp & Sambaibinha & Davilla rugosa \\
\hline
\end{tabular}

Fonte: Carmo et al., (2007)

Para um maior sucesso de sobrevivência dessas espécies, o plantio deve ser realizado no início das chuvas (novembro), caso não seja possível, recomenda-se providenciar irrigação para os 3 três meses iniciais das mudas no campo.

\section{CONCLUSÃO}

Por meio do diagnóstico ambiental avaliou-se que o Córrego Sussuapara apresenta áreas onde houve a supressão da mata de galeria, que teve como efeito o encadeamento de diversos impactos ambientais. $\mathrm{O}$ aspecto mais atingido foi o meio biótico, fauna e flora, e físico, fator água.

As medidas mitigadoras propostas foram isolar a área dos fatores de degradação, eliminar a emissão de efluentes e deposição de resíduos sólidos, retirar as espécies invasoras e conduzir a regeneração natural e/ou enriquecimento da área.

\section{REFERENCIAS}

BARBOSA, J. A.; et al.; O Sensoriamento Remoto na proposição de plano de uso em unidades de conservação: estudo de caso. Disponível em:

http://www.obt.inpe.br/cbers/cbers_XIISBSR/415_INIC_artigo\%20uso.pdf Acessado em: 22 de julho de 2016.

BIZZO, M. R. de O.; MENEZES, J.; ANDRADE, S. F de. Protocolos de avaliação rápida de rios (PAR). Caderno de Estudos Geoambientais - CADEGEO, v.4, n.1, p. 05-13, 2014.

BRASIL. Ministério do Meio Ambiente, Agência Nacional de Águas, Programa das Nações Unidas para o Meio Ambiente. Cuidando das águas: soluções para melhorar a qualidade dos recursos hídricos. 2. ed. Brasília: ANA, 2013. Disponível em:

http://arquivos.ana.gov.br/institucional/sge/CEDOC/Catalogo/2013/CuidandoDasAguasSolucao2aEd.pdf . Acesso em: 20 jul. 2016.

BRASIL. Resolução do CONAMA nº 01 de 23 de Janeiro de 1986. Dispõe sobre as diretrizes gerais para uso e implementação de Avaliação de Impactos Ambientais.

CARMO, D. F. do et al.; Nascente do Córrego Suçuapara - um espaço para a educação escolar. ETD Educação Temática Digital, v.8, n.2, p. 90-110, jun. 2007. 
CARNEIRO. R. F. V. et al.; Atributos dos fungos micorrízicos arbusculares como indicadores de áreas degradadas e em recuperação no estado do Piauí. Rev. Bras. de Agroecologia. v.11, n.2, p. 61-69. 2016.

CREMONEZ, F. E., et al. Avaliação de impacto ambiental: metodologias aplicadas no Brasil. Revista Monografias Ambientais - REMOA v.13, n.5, dez. 2014, p.3821-3830 Revista do Centro do Ciências Naturais e Exatas - UFSM, Santa Maria e-ISSN 2236 1308. Disponível em: http://cascavel.ufsm.br/revistas/ojs-2.2.2/index.php/remoa/article/viewFile/14689/pdf Acessado em: $11 \mathrm{de}$ abril de 2016.

FOLEY, J.A. et al. Global consequences of land use. Science, v.309, n.5734, p.570-574, 2005

GONÇALVES, D.S.et al. DIAGNÓSTICO AMBIENTAL E PROPOSTA DE PLANO DE RECUPERAÇÃO DA APP, FAZENDA SANTA JULIANA, CARIRI DO TOCANTINS - TO. Nucleus, Ituverava, v. 13, n. 1, p. 261-276, apr. 2016. ISSN 1982-2278. Disponível em: <http://www.nucleus.feituverava.com.br/index.php/nucleus/article/view/1562/1983> . ISSUE DOI: 10.3738/1982.2278.1562. Acesso em: 15 abr. 2016.

LEOPOLD, L. B. et al. A producer for evaluating environmental impact. Washington, D.C.: U.S. Geol. Surv. Circ. U.S.G.C, 1971. 355 p.

LIMA, W.P.; ZAKIA, M.J.B. Hidrologia de Matas Ciliares. In: RODRIGUES, R.R.; LEITÃO-FILHO, H.F. (ed.). Matas ciliares: conservação e recuperação. São Paulo: Edusp e Fapesp, 2. ed, 2004. p.33-44 .

LUANE SILVA, J. et al., Diagnóstico ambiental como subsídio à restauração florestal e manutenção hidrológica da bacia do ribeirão dos pinheirinhos, Brotas - SP. Irriga, Botucatu, v. 21, n. 1, p. 1-13, jan.mar., 2016

MATIELLO, H. N. et al.; Evolução da recuperação de um trecho de mata ciliar do Rio Santa Maria do Rio Doce com potencial uso agroecológico. Cadernos de Agroecologia - ISSN 2236-7934 - v.10, n. 3 de 2015.

MESQUITA MONTEIRO, G.; RAMOS OLIVEIRA, E.; Propriedades rurais nas margens dos Rios Parnaíba e Poti (zona norte de Teresina-PI) e seus reflexos na manutenção da mata ciliar. REVISTA GEONORTE, Edição Especial 4, V.10, N.1, p.442-445, 2014. (ISSN 2237-1419)

NERES, N. G. C. et. al. Avaliação ambiental e indicação de medidas mitigadoras para a nascente do Córrego Mutuca, Gurupi-TO. Enciclopédia Biosfera, Centro Científico Conhecer - Goiânia, v.11 n.21; p. 2824. 2015.

NUNES, H.K.B.; GOMES, M.L.; PAULA, J.E.A.; Assoreamento e formação de bancos de areia no leito do rio Parnaíba, na zona urbana de Teresina-Piauí. REVISTA GEONORTE, Edição Especial 4, v.10, n.1, p.156-160, 2014.

OLIVEIRA, A. L. de, et. al. Análise Qualitativa dos Impactos Ambientais no Meio Abiótico em um Depósito de Resíduos Sólidos. Enciclopédia Biosfera, Centro Científico Conhecer - Goiânia, v.11 n.22; p. 184. 2015. a

OLIVEIRA, A. L. de.et al. Proposta de recuperação para a nascente do córrego mutuca em Gurupi - TO. Enciclopédia Biosfera, Goiânia, v. 11, n. 22, p.2447-2465, dez. 2015. b

PIMENTA, R. H. O. et al.; Diagnóstico ambiental em três trechos distintos do Córrego Capão, Regional Venda Nova, Município de Belo Horizonte/MG. Revista Ipetra. v. 2, n. 1, p. 153-173, jan./jul. 2016

PALMAS. Prefeitura Municipal De Palmas, Plano Municipal de Saneamento Básico - PMSB | Volume III, disponível em: < 
http://www.palmas.to.gov.br/media/doc/arquivoservico/PMSB_Palmas_Volume_03_Drenagem_Urbana_ Versao_Final_1.pdf> acessado em: 24 de julho de 2016.

REIS, A. da. S.et al. Impactos ambientais diagnosticados na nascente do córrego San rival- fazenda meu paraíso, Palmeirópolis - Tocantins. Enciclopédia Biosfera, Goiânia, v. 11, n. 21, p.3166-3184, jun. 2015. Disponível em: http://www.conhecer.org.br/enciclop/2015b/multidisciplinar/impactos\%20ambientais.pdf Acessado em: 25 jul. 2016.

RIZZETI, D. M.et al. Impactos Ambientais na sub-bacia hidrográfica do Rio Soturno decorrentes do desmatamento da mata ciliar. In: FÓRUM INTERNACIONAL ECOINOVAR, 3. Anais.... Santa Maria/RS - 3 a 4 de Setembro de 2014.

SÁNCHEZ, L. E. Avaliação de impacto ambiental: conceitos e métodos. São Paulo: Oficina de Textos, 2006. 495p.

SILVA JUNIOR, J. L. C., Avaliação parcial das condições pluviométricas no Estado do Tocantins, durante o período chuvoso 2015/2016. Relato técnico-científico. Fundação Universidade do Tocantins UNITINS. Fev. 2016. Disponível em: < https://central3.to.gov.br/arquivo/267988/> Acessado em: 21 out. 2016.

SILVA, E. Avaliação qualitativa de impactos ambientais do reflorestamento no Brasil. 1994. 309f. Tese (Doutorado em Ciências Florestais) - Universidade Federal de Viçosa, Viçosa.

SOUZA, J. L,; SILVA, I. R.; Avaliação da qualidade ambiental das praias da ilha de Itaparica, Baía de Todos os Santos, Bahia. Soc. \& Nat., Uberlândia, v.27, n.3, p. 469-484, set/dez/2015.

SOUZA, V. G. de.; BULHÕES, E. M. R. Avaliação ambiental através de protocolo de avaliação rápida no baixo leito do rio Paraíba do Sul, no município de Campos dos Goytacazes/RJ. Caderno de Estudos Geoambientais - CADEGEO. v.06, n.01, p.32-50, 2015

SPADOTTO, C.A. Classificação de impacto ambiental. Comitê De Meio Ambiente. Sociedade Brasileira da Ciência das Plantas Daninhas. 2002. [online] Disponível: http://www.cnpma.embrapa.br/herbicidas/ Acessado em: 22 jul. 2016.

TOMMASI, L. R. Estudo de Impacto Ambiental. São Paulo: CETESB: Terragraph Artes e Informática, 1993.

VAZ, L.; ORLANDO, P.H.K. Importância das matas ciliares para, manutenção da qualidade das águas de nascentes: Diagnóstico do Ribeirão Vai-Vem de Ipameri- GO. In: ENCONTRO NACIONAL DE

GEOGRAFIA AGRÁRIA, 21, 2012, Uberlândia-MG. Anais eletrônico... Uberlândia-MG: UFU. 2012.

VON SPERLING, M. Introdução à qualidade das águas e tratamento de esgotos. 3. ed. 452p. Belo Horizonte: UFMG, 2005. 
